\title{
Construction of a Glucose Biosensor by Immobilizing Glucose Oxidase within a Poly(o- phenylenediamine) Covered Screen-printed Electrode
}

\author{
Miao Yuqing, Chen Jianrong, Wu Xiaohua \\ College of Chemistry and Life Science, Zhejiang Normal University \\ Jinhua 321004, China
}

\begin{abstract}
The glucose biosensors were prepared by the electropolymerization of the non-conductive polymer, Poly(o-phenylenediamine), onto a planar screen-printed electrode. A fabrication procedure was performed to decrease the waste of expensive enzyme. The amperometric glucose response was measured by the potensiostating of the prepared glucose biosensors at a potential of $0.3 \mathrm{~V}$ with ferrocene as mediator. Results show that the obtained biosensors have a linear range up to $25 \mathrm{mM}$ glucose, fast response time (100s) and high sensitivities $(16.6 \mathrm{nA} / \mathrm{mM})$. Also, the effects of applied potential and sweeping number of Cyclic voltammograms for electropolymerization were systematically investigated and optimal values were recorded.
\end{abstract}

Key words: Poly(o-phenylenediamine), non-conducting polymer, biosensor, glucose

\section{INTRODUCTION}

Since the pioneering work of Clark and Lyons ${ }^{[1]}$, the integration of an enzyme into an electrode attracted much interest in the development of biosensors up to now ${ }^{[2-6]}$. The advantages associated with these devices are safety, simplicity, minimal sample preparation, easy to handle, economy, accuracy, precision, and high sensitivity as well as the possibility of developing compact and portable analyzers ${ }^{[7,8]}$.

In recent years, there has been a growing interest in immobilizing biomolecules in electropolymerized films to develop biosensors. The electropolymerization of electrically (non-)conducting polymers, such as poly(3aminophenol), poly(1,3-diaminozenzene), polyphenol, polyaniline, polyacetylene, polyindole or polypyrrole, is an interesting and effective procedure to prepare biosensors due to its simple preparation, easy miniaturization, and the precise localization of biomolecules $^{[9-11]}$. Also the thickness of the resulting film could be controlled easily ${ }^{[12]}$.

The electrochemical method involves the entrapment of biomolecules in organic polymers during their electrogeneration on an electrode surface. For most of research, the electrodes were dipped into the solution containing enzymes and monomer for copolymerization. One of the main disadvantages is that only a few enzymes in solution could be immobilized successfully and most expensive enzymes are disused [13,14]

In this research, a screen-printed planar electrode was used to fabricate the amperometric glucose biosensors by immobilizing GOD into the electropolymerized PPD film with ferrocene as an electron transfer mediator. Enzyme was dried on the surface of electrode before PPD film was formed.
Therefore, most of enzyme was constrained under formed PPD film. In addition, only $20 \mu 1$ enzyme was needed to cover the electrode surface. Few enzymes would be wasted in this study.

\section{MATERIALS AND METHODS}

Reagents: The enzyme glucose oxidase (GOD) from Aspergillus niger (EC 1.1.3.4, 158 units/mg of solid, type II) was obtained from Sigma Chemical Co. The monomer o-phenylenediamine (o-PD) for the electropolymerization was obtained from SCRC (Shanghai, China). PBS (pH 7.2) containing 0.01 M phosphate buffer, $0.137 \mathrm{M} \mathrm{NaCl}$ and $2.7 \mathrm{mM} \mathrm{KCl}$ was used as running buffer. GOD and ferrocene were prepared in PBS.

Apparatus: Electropolymerizations, amperometric measurements, and cyclic voltammetry (CV) were carried out with CHI 650A electrochemical workstation. Screen-printed electrodes were used for all electrochemical experiments. Working electrodes and counter electrodes were made of conductive carbon ink. One naked silver band was performed in $0.01 \mathrm{M} \mathrm{FeCl}_{3}$ solution for $10 \mathrm{~min}$ to fabricate a reference electrode.

Preparation of glucose biosensors: Firstly, $20 \mu \mathrm{l}$ $1 \mathrm{mg} / \mathrm{ml} \mathrm{GOD}$ and $20 \mu \mathrm{l} 0.5 \mathrm{mM}$ ferrocene were applied on the surface of electrodes. After drying, o-PD was dropped on the electrode to cover the below enzyme and ferrocene, and then the electropolymerization is performed by voltage cycling between -0.2 and $0.8 \mathrm{~V}$ vs $\mathrm{Ag} / \mathrm{AgCl}$ and a scan rate of $50 \mathrm{mV} / \mathrm{s}$ for a certain number of cycles. Unless otherwise indicated, $20 \mu \mathrm{l}$ of a $5 \mathrm{mM}$ o-PD in PBS ( $\mathrm{pH}$ 7.2) is used for the procedure. The resulting biosensors were rinsed with 
0.01 M PBS ( $\mathrm{pH}$ 7.2) to remove un-immobilized enzymes, and were stored at $4{ }^{\circ} \mathrm{C}$ when not in use.

Measurements: Cyclic voltammogram measurements were carried out in $0.01 \mathrm{mM}$ PBS ( $\mathrm{pH}$ 7.2). Amperometric responses of the fabricated biosensors to glucose were studied by injections of aliquots of the glucose stock solution, and the resulting oxidation currents were monitored. All measurements were carried out at room temperatures.

\section{RESULTS and DISCUSSION}

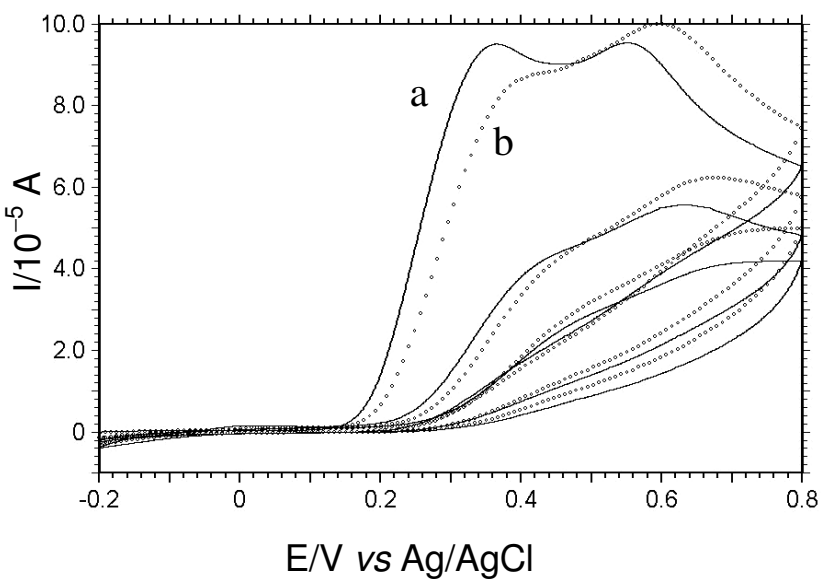

Fig. 1: Cyclic voltammograms of the electropolymerization of $5 \mathrm{mM}$ o-PD in $0.01 \mathrm{M}$ PBS $(\mathrm{pH}$ 7.2) in the absence (a) and presence (b) of GOD. Sweep rate, $50 \mathrm{mV} / \mathrm{s}$.

The electropolymerization was performed by cyclic voltammetry between -0.2 and $0.8 \mathrm{~V}$ and a scan rate of $50 \mathrm{mv} / \mathrm{s}$, using a $5 \mathrm{~mm}$ o-PD solution in $0.01 \mathrm{M}$ PBS (pH 7.2). The results are shown in Fig. 1. The initial CV curve shows two irreversible oxidation peak at 0.35 $\mathrm{V}$ and $0.55 \mathrm{~V}$ corresponding to the polymerization of oPD. On the successive cycles, however, the peak currents decreases, indicating that electropolymerization is a self-limiting process and the oxidation of o-PD may produce a compact and insulting film of PPD, which prevents from further deposition of polymer $^{[15]}$. After first cycle, a pair of newly formed redox peaks could be observed at -0.2 and $0 \mathrm{~V}$, which corresponds to the reduction and oxidation of PPD film. The detailed information of polymer structure and the polymerization mechanism could be found in the previous report $^{[16]}$.

The enzyme should be kept in neutral $\mathrm{pH}$ for optimum activity, so a buffer of $\mathrm{pH} 7.2$ was chose for the electropolymerization of PPD to cover the enzyme. Fig. 1b shows the CV of the electropolymerization of PPD with GOD presence on the electrode surface. Compared with Fig. 1a, two irreversible oxidation peaks at $0.35 \mathrm{~V}$ and $0.55 \mathrm{~V}$ shifts to more positive potential at 0.4 and $0.6 \mathrm{~V}$ in the presence of GOD.
Also, the first oxidation peak decreases and the second oxidation peak increases due to the presence of GOD.

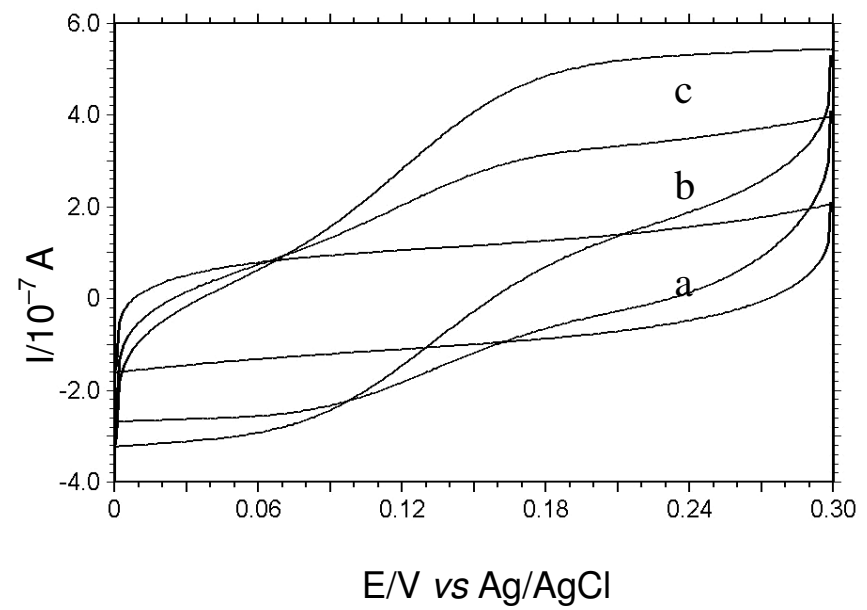

Fig. 2 Cyclic voltammograms of the PPD covered screen-printed electrodes with (a) only GOD; (b, c) GOD and ferrocene immobilized in PBS ( $\mathrm{pH} 7.2$ ) in the absence (a, b) and presence (c) of $35 \mathrm{~mm}$ glucose.

Fig. 2 shows the cyclic voltammograms obtained from the enzyme electrode in PBS ( $\mathrm{pH}$ 7.2). Without glucose, the enzyme contributes no response and the GOD electrode only exhibits the quasi-reversible electrochemical behavior of ferrocene/ferricnium redox couple (Fig. 2b). The oxidation current is increased to a large extent in the presence of glucose (Fig. 2c), which is indicative of the enzyme-dependent catalytic reduction of the ferricinium ion produced at oxidizing potential $^{[17]}$. Ferrocene molecules works well as an electron transfer mediator between the electrode substrate and the redox center of GOD.

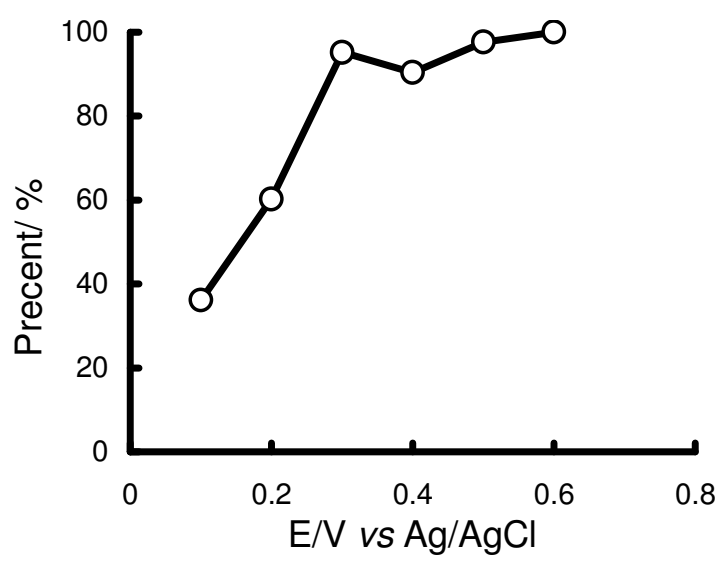

Fig. 3 Current response of biosensors to $20 \mathrm{mM}$ glucose in PBS ( $\mathrm{pH} 7.2$ ) for various potentials.

The effect of applied potential on the biosensor response is shown in Fig. 3. The electrode response to glucose begins to increase at $0.1 \mathrm{~V}$ with the change of applied potential and becomes nearly constant at 
potentials in the range of 0.3 to $0.6 \mathrm{v} v \mathrm{Ag} / \mathrm{AgCl}$. The significant increased sensitivity with applied potential from 0.1 to $0.3 \mathrm{mV}$ is attributed to the increased driving force for the oxidation of ferrocene to ferricinium. A further increase of the potential resulted in little change in current response. The potential of $0.3 \mathrm{~V}$ was selected for the following experiments so as to achieve the greatest sensitivity and relatively low background signal.

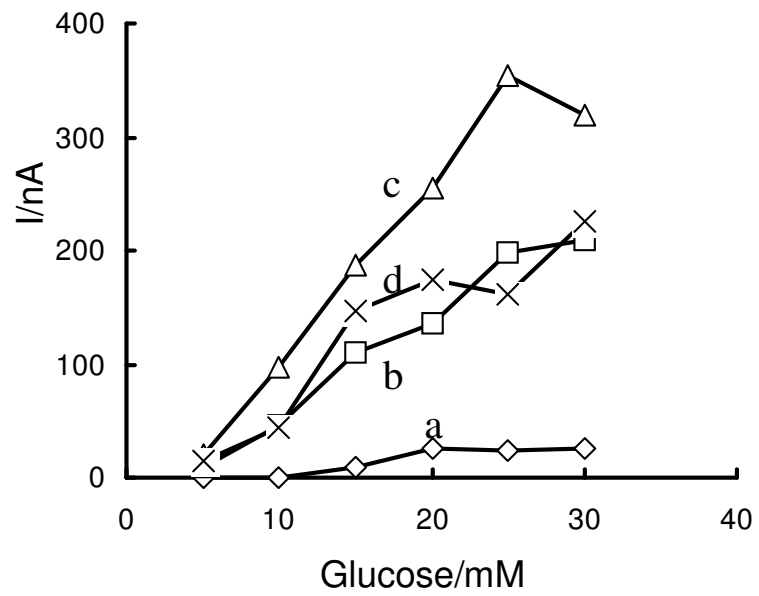

Fig. 4 Comparison of the current response of glucose biosensors with different concentration of ferrocene of (a) 0.1 ; (b) 0.25 ; (c) 0.5 and (d) $1 \mathrm{mM}$. Polarized potential, $0.3 \mathrm{~V}$.

Normally, substrate $\left(\mathrm{O}_{2}\right)$ or product $\left(\mathrm{H}_{2} \mathrm{O}_{2}\right)$ of GOD enzyme reaction can be monitored for the development of glucose biosensors ${ }^{[18,19]}$. The simplest method is to detect the consumption of oxygen at negative potentials $(-0.6 \mathrm{~V}$ vs $\mathrm{Ag} / \mathrm{AgCl})$. However, the oxygen in the sample interferes the result of detection and such biosensors are not suitable for low analyte concentration. Another way is to detect of the oxidization of $\mathrm{H}_{2} \mathrm{O}_{2}$. A lot of reductants (for example, ascorbate, billirubins, acetaminophen ets) in biological liquids are able to be oxidized at the same potential and produce high noise signal ${ }^{[20]}$. Soluble or immobilized mediators have been developed to shuttle electron between active center of enzyme and electrode surface. Ferrocene was employed in this study for the development of glucose biosensor. Fig. 4 indicates that the current response of the biosensor increases sharply with the increase of the concentration of mediator from 0.1 to $0.5 \mathrm{mM}$. The biosensor response is limited by the enzyme-mediator kinetics at low mediator concentration and enzyme-substrate kinetics at high concentration of mediator. Higher levels of ferrocene concentration did not improve the signal response further and in fact caused the increase of background current, therefore, the concentration of ferrocene was set at $0.5 \mathrm{mM}$ for all further work.

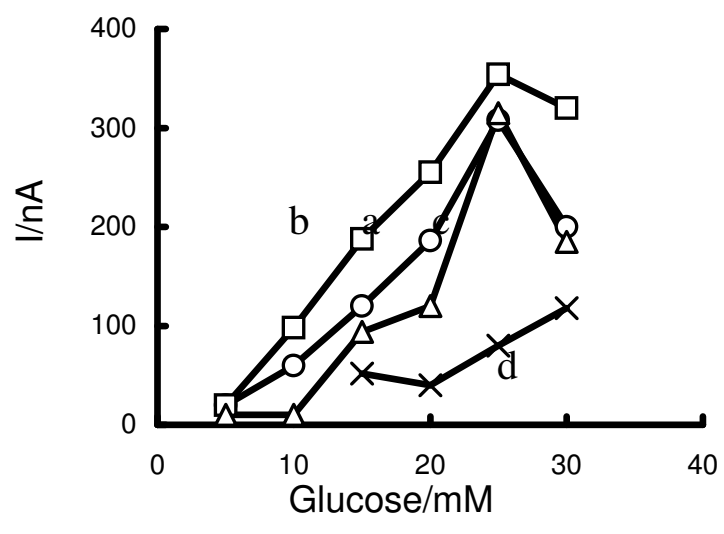

Fig. 5 The sensitivity of biosensors to glucose, which were prepared from (a) 2; (b) 3; (c) 4; (d) 5 circles of $\mathrm{CV}$ for PAN polymerization.

How the thickness of PPD film influences the final property of glucose biosensors was studied by changing the circle number of CV sweep for PPD polymerization (Fig. 5). Since most of charges for electropolymerization are consumed at the first several cycles, the 2, 3, 4, 5 cycles of $\mathrm{CV}$ were studied. When the scan cycle is only 2 cycles, the polymer film obtained is too loose or too thin to obtain a high amount of GOD. The biosensor prepared from 3 cycles of CV gives the highest sensitivity, and then the sensitivity decreases with the increase of cycles. It means that the non-conducting PPD film prevents the electron shuttle between GOD and electrode surface. Considering the sensitivity of biosensor, 4 circles of $\mathrm{CV}$ for PPD polymerization were chosen.

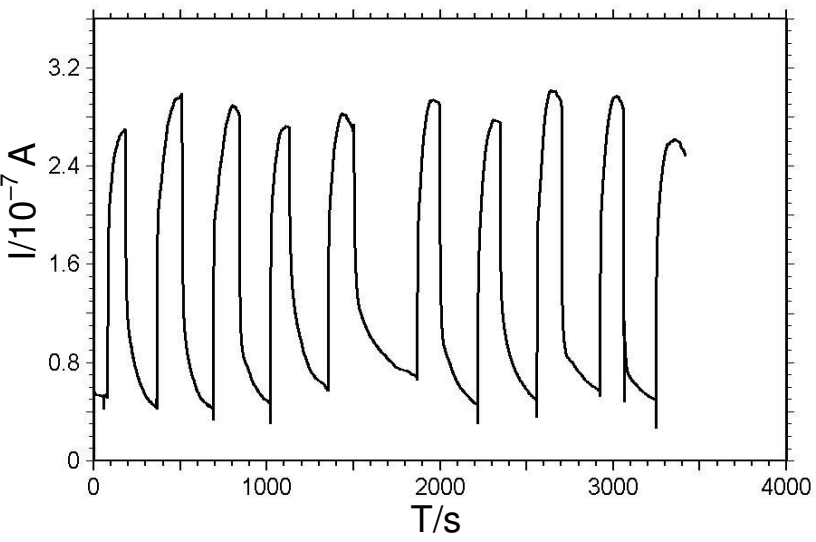

Fig. 6 The typical responses of a biosensor to glucose of $20 \mathrm{mM}$ at $0.3 \mathrm{~V}$.

When the glucose biosensor was polarized at $0.3 \mathrm{~V}$ vs $\mathrm{Ag} / \mathrm{AgCl}$ and then a glucose solution was added into PBS ( $\mathrm{pH}$ 7.2), a gradual increase in the oxidation current was observed (Fig. 6). The oxidation current 
reached a stable steady-state value within $100 \mathrm{~s}$. The repeatability of response of a typical glucose enzyme biosensor was investigated at a glucose concentration of $20 \mathrm{mM}$. The mean current was $231 \mathrm{nA}$ with a rsd. of $6.2 \%(\mathrm{n}=10)$. Fig. 7 shows the experimental calibration curve of the current response against glucose concentration with experimental condition chosen above. The linear range is $5-25 \mathrm{mM}$ glucose and the sensitivity at $0.3 \mathrm{~V}$ is $16.6 \mathrm{nA} / \mathrm{mM}$.

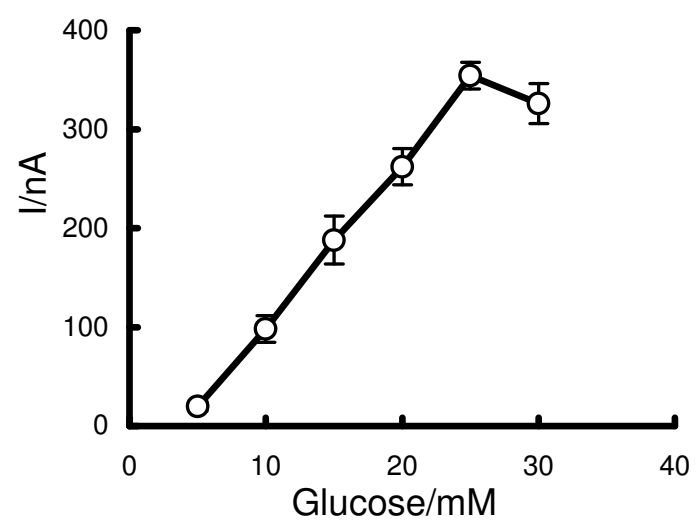

Fig. 7: The steady-state anodic currents at $0.3 \mathrm{~V}$ plotted against glucose concentration.

\section{CONCLUSION}

In this study, the electropolymerized nonconducting PPD film was used to immobilize GOD for the development of a glucose biosensor. GOD was dried on the surface of electrode before the electropolymerization of PPD. The procedure is simple and repeatable. Especially, the procedure decreases the waste of expensive enzyme.

\section{ACKNOWLEDGMENTS}

This material is based upon work funded by the National Natural Science Foundation of China (Grant No. 90406016), State Key Laboratory of Electroanaytical Chemistry of Chinese Academy of Sciences, Science and Technology Department of Zhejiang Provice.

\section{REFERENCES}

1. Clark, L. C. and Lyons C., 1962. Electrode systems for continuous monitoring in cardiovascular surgery. Ann. N. Y. Acad. Sci., 102: 29-35
2. Wang J., 1999. Amperometric biosensors for clinical and therapeutic drug monitoring: a review. Journal of Pharmaceutical and Biomedical Analysis, 19: 47-53

3. Luppa P. B., Sokoll L. J. and Chan D. W., 2001. Review: immunosensors-principles and applications to clinical chemistry. Clinica Chimica Acta, 314: 1-26

4. Albareda-Sirvent M., Merkoçi A. and Alegret S., 2000. A review: Configurations used in the design of screen-printed enzymatic biosensors. Sensors and Actuators B, 69 (1-2): 153-163

5. Alocilja E. C. and Radke S. M., 2003. Industry review: Market analysis of biosensors for food safety. Biosensors and Bioelectronics, 18 (5-6): 841-846

6. Leonard P., Hearty S., Brennan J., Dunne L., Quinn J., Chakraborty T. and O'Kennedy R., 2003. Review: advances in biosensors for detection of pathogens in food and water. Enzyme and Microbial Technology, 32 (1): 3-13

7. Lauks I. R., 1998. Microfabricated Biosensors and Microanalytical Systems for Blood Analysis. Acc. Chem. Res., 31: 317-324

8. Manz A., Graber N. and Widmer H. M., 1990. Miniaturized total chemical analysis system: a novel concept for chemical sensing. Sens. Actuators B, 1: 244-248

9. Nakabayshi Y., Wakuda M. and Imai H., 1998. Amperometric glucose sensors fabricated by electrochemical polymerization of phenols on carbon paste electrodes containing ferrocene as an electron transfer mediator. Analytical Sciences, 14: 1069-1076

10. Chung T. D., Jeong R., Kang S. K. and Kim H. C., 2001. Reproducible fabrication of miniaturized glucose sensors: preparation of sensing membranes for continuous monitoring. Biosensors \& Bioelectronics, 16: 1079-1087

11. Gerard M., Chaubey A. and Malhotra B. D., 2002. Review: Application of conducting polymers to biosensors. Biosensors and Bioelectronics, 17 (5): 345-359 
12. Cosnier S., 1999. Biomolecule immobilization on electrode surfaces by entrapment or attachment to electrochemically polymerized films: a review. Biosensors \& Bioelectronics, 14: 443-456

13. Nakabayashi Y. and Yoshikawa H., 2000. Amperometric biosensors for sensing of hydrogen peroxide based on electron transfer between horseradish peroxidase and ferrocene as a mediator. Analytical Sciences, 16: 609-614

14. Klinchan S., Chotiwongpipat W., Suwannakum T., Tanticharoen M. and Kirtikara K., 2002. Construction of sensor chip by electrochemicalpolymerization techniques for sucrose determination. The Journal of KMITNB, 12 (1): $12-17$

15. Deng Q. and Dong S., 1994. Mediatorless hydrogen peroxide electrode based on horseradish peroxidase entrapped in poly(o-phenylenediamine). Journal of Electroanalytical Chemistry, 377: 191195.
16. Jang D., Yoo Y. and Oh S. M., 1995. Electropolymerization mechanism for poly(ophenylenediamine) (PPD) and its electrocatalytic behavior for $\mathrm{O}_{2}$ reduction. Bull. Korean Chem. Soc., 16 (5): 392-397

17. Miao Y. and Tan S. N., 2001. Amperometric Glucose Biosensor Based on Immobilization of Glucose Oxidase in Chitosan Matrix Cross-linked with Glutaraldehyde. Electroanalysis, 13(4): 347349

18. Bott A. W., 1998. Electrochemical methods for the determination of glucose. Current Separations, 17 (1), 25-32

19. Wang J., 2001. Review: glucose biosensors: 40 years of advances and challenges. Electroanalysis, 13 (12): 983-989

20. Karyakin A. A., Gitelmacher O. V. and Karyakina E. E., 1995. Prussian blue-based first-generation biosensor. A sensitive amperometric electrode for glucose. Anal. Chem., 67, 2419-2423 